\title{
The future of psychiatric epidemiology
}

\author{
MYRNA M. WEISSMAN
}

I am honored to be a member of the International Advisory Board of the new Italian journal on epidemiology and social psychiatry. The topic of the journal and the presence of an international board is a reflection of the rapid developments in epidemiology and the refinement of epidemiologic methods that now make cross-national comparisons using similar methods a reality. In the past, the conventional wisdom was that two psychiatrists couldn't agree on the diagnosis of any one patient. Given this situation, comparisons between countries on the rates, the risk factors, the natural history, and the clinical phenomena of specific psychiatric disorders based on community samples across countries were unobtainable goals. The landmark World Health Organization (WHO) studies in the 1960s and 70s demonstrated that the major differences in the US-UK rates of the major psychiatric disorders were mostly due to differences in methodology and were not real differences in rates between countries. The WHO then launched a series of studies looking at schizophrenia and depression based on clinical samples in a variety of countries.

With the exception of a few studies in Europe and Scandinavia, epidemiologic approaches were infrequently applied to the study of psychiatric disorders in the community until the 1970s. The major obstacle was the lack of specification of the diagnostic criteria and, again, the difficulty of obtaining reliable diagnoses in large community samples. The period after World War II in the United States was one of considerable activity in research on the epidemiol-

Indirizzo per la corrispondenza: Professor M. M. Weissman, College of Physicians and Surgeons of Columbia University, Director, Division of Clinical and Genetic Epidemiology, New York State. Psychiatric Institute, 722 West 168th Street, Box 14, New York, NY 10032 (USA).

Fax $(+1) 212-568.3534$. ogy of mental impairment and health, and several classic studies were completed which looked at the relationship between social class and mental illness, the effects of changing values in small towns, and effects of urban life (see Dohrenwend et al., 1980 for review). These studies used sophisticated statistical and sampling techniques and demonstrated the importance of poverty and social stress in the development of psychiatry impairment. However, the symptom or impairment scales used could not generate rates of specific psychiatric disorders, and the findings from these studies did not have a major impact on clinical psychiatry.

Psychiatric epidemiology and clinical psychiatry did not begin to converge until the mid-1970s. The introduction into psychiatry of specified diagnostic criteria with standardized methods of assessing signs and symptoms of psychiatric disorders necessary to make the criteria provided the technology for systematic diagnosis in epidemiologic studies. These methods were first applied in the US in 1975 in a small community study of 500 subjects living in New Haven, Connecticut and were shown to be feasible and reliable (Weissman \& Myers, 1978). In the late 1980s, partially given impetus by the US government's interest in planning mental health programs in the community, the National Institute of Mental Health (NIMH) Epidemiologic Catchment Area Study (ECA) was initiated, using the Diagnostic Interview Schedule (DIS), a new diagnostic instrument developed by Lee Robins specifically for large-scale epidemiologic studies of psychiatric disorders (Robins et al., 1981; Robins \& Regier 1991). The purpose of the ECA study was the collect data on rates, risk factors, and treatment patterns of the major mental illnesses in the community. The ECA was based on over 18,000 adults living in five communities in the United States. 
As knowledge of the ECA grew, similar studies using identical methodology were undertaken in different parts of the world. In many cases, the staff in other countries were trained in the use of th DIS by Dr. Lee Robins and her team in St. Louis, Missouri. Thus, for the first time, independent cross-national comparisons of epidemiologic rates using data obtained with similar methods became possible. Epidemiologic studies in many parts of the world, using the DIS, were undertaken. These included studies in Edmonton, Canada (Bland et al., 1988); Puerto Rico (Canino et al., 1987); Seoula, Korea (Lee et al., 1987); Taiwan (Hwu et al., 1989); Florence, Italy (Faravelli et al., 1990); New Zealand (Joyce et al., 1990); Paris, Frances (Lepine et al., 1989); Lebanon (Karam, 1991); Munich, Germany (Wittchen et al., 1991). The results of these studies, which are just beginning to be published, emphasize the similarities rather than the differences in rates and patterns of the major mental illnesses. With the exception of Taiwan, which seems to have lower rates for most psychiatric disorders, there is some remarkable similarities in patterns, although the full data are not yet in.

In a parallel development in the 1980 s, my husband, Gerald L. Klerman, M. D., at Cornell Medical Center in New York City undertook scientific leadership for a major cross-national study on the treatment of panic disorder, which included 30 countries (Klerman, 1988). The training site for the diagnostic assessment used in this study was in Professor Giovanni Cassano's unit in Pisa, Italy, which was also one research site. The availability of these standardized methods for assessing diagnosis, the use of standardized criteria, common training program, and translations allowed for the conduct of this study across many countries of different cultures.

The cross-national study of panic disorder and the epidemiologic studies are all based on the American diagnostic system of DSM-III. The American system of DSM-III or its forthcoming DSM-IV is not universally used, and a new diagnostic method, the Schedule for Clinical Assesment in Neuropsychiatry (SCAN) is being field-tested in 20 centers in 11 countries (Wing et al., 1990). The aim of this method is to develop a comprehensive procedure for clinical examination that is also capable of generating many of the categories of the international classification of disease (10th edition, ICD-10), as well as the DSM-III and IV. The Composite International Diagnostic Interview (CIDI), based on the DSM-IV and the ICD, has also been developed and is being field-tested
(Robins et al., 1988). These two instruments are complementary in that the CIDI is designed for use in large-scale community surveys that necessitate the use of lay interviewers whereas the SCAN can be used in its full-form by clinically trained professionals. The availability of these two diagnostic methods that bridge the major classification systems will definitely facilitate future cross-national comparative studies. Diagnostic system imperialism can be avoided in future studies.

The appearance of this new Journal comes at a propitious time when we are about to learn the full results of these cross-national comparative epidemiologic studies. While the early results have shown similarities between countries, finer analyses are still underway to try to understand some of the differences. For example, are the increasing rates of depression and earlier age of onset in the cohorts born since World War II universal findings in countries with different social and historical perspectives (Klerman \& Weissman 1989)? The availability of these data may allow us to understand some of the historical, cultural, and economic factors which impact on the rates of depression.

Involvement in these cross-national endeavors have had their personal rewards. It has been an opportunity to work with, understand, and befriend people from many parts of the world. The availability of fax and computer mail have overcome technical problems in cross-national collaborations. However, the collaborations have been nutured by the sharing of culture, art, monuments, food and friendship. The opportunity to experience the beauty of Italy and the hospitality of the Italians whith my husband in the course of our work has been a treasured reward.

\section{REFERENCES}

Bland R. C., Orn H. \& Newman S. C. (1988). Lifetime prevalence of psychiatric disorders in Edmonton. Acta Psychiatrica Scandinavica, 77, 24-32.

Canino G. J., Bird H. R., Shrout P. E., Rubio-Stipec M., Bravo M., Martinez R., Sesman M. \& Guevara L. M. (1987). The prevalence of specific psychiatryc disorders in Puerto Rico. Archives of General Psychiatry 44, 727-735.

Dohrenwend B. P., Dohrenwend B. S., Gould M. S., Link B., Neugebauer R. \& Wunsch-Hitzig R. (1980). Mental Illness in the United States: Epidemiological Estimates. Praeger Publishers: New York.

Faravelli C., Degl'Innocenti G., Aiazzi L., Incerpi G. \& Pallanti 
S. (1990). Epidemiology of mood disorders: a community survey in Florence. Journal of Affective Disorders, 20, 135-141.

Hwu H. G., Yeh E. K. \& Chang L. Y. (1989). Prevalence of psychiatric disorders in Taiwan defined by the Chinese Diagnostic Interview Schedule. Acta Psychiatrica Scandinavica 79, 136-147.

Joyce P. R., Oakely-Brown M. A., Wells J. E., Bushnell J. A. \& Hornblow A. R. (1990). Birth cohort trends in major depression: increasing rates and earlier onset in New Zeland. Journal of Affective Disorders, 18, 83-90.

Karam E. (1991). Presented at the ITSS, Washington, D.C., October 1991; Karama E., Barakeh M., Karam A. N. \& El-Khouri N. Revue Médical Libanaise 3, 28.

Klerman G. L. (1988). Overview of the cross-national collaborative panic study. Archives of General Psychiatry 45, 407, 412.

Klerman G. L. \& Weissman M. M. (1989). Increasing rates of depression. Journal of the American Medical Association 261, 2229-2235.

Lee C. K., Han J. H. \& Choi J. O. (1987). The epidemiological study of mental disorders in Korea (IX): alcoholism, anxiety, and depression. Seoul Journal of Psychiatry 12, 183-191.

Lepine J. P., Lellouch J., Lovell A., Therani M., Ha C., VerdierTaillefer M. H., Rambourg N. \& Lemperiere T. (1989). Anxiety and depressive disorders in a French population: metho- dology and preliminary results. Psychiatry and Psychobiology 4, 267.274.

Robins L. N. \& Regier D. A. (eds.) (1991). Psychiatric Disorders in America: the Epidemiologic Catchment Area Study. Free Press: New York.

Robins L. N., Helzer J. E., Croughan J. \& Ratcliff K. S. (1981). National Institute of Mental Health diagnostic interview schedule. Archives of General Psychiatry 38, 381-389.

Robins L. N., Wing J., Wittchen H. U., Helzer J. E., Babor T. F. et al. (1988). The composite international diagnostic interview: an epidemiologic instrument suitable for use in conjunction with different diagnostic systems and in different cultures. $\boldsymbol{A r}$ chives of General Psychiatry 45, 1069-1077.

Weissman M. M. \& Myers J. K. (1978). Affective disorders in a US urban community. Archives of General Psychiatry 35, 1304-1311.

Wing J. K., Babor T., Brugha T., Burke J. \& Cooper J. E. (1990). SCAN: schedules for clinical assessment in neuropsychiatry. Archives of General Psychiatry 47, 589-592.

Wittchen H. U., Essau C. A. \& Krieg J. C. (1991). Anxiety disorders: similarities and differences of comorbidity in treated and untreated groups. British Journal of Psychiatry, Supplementum No. 12, 159, 23-33. 


\section{NE' IL BIANCO NE' IL NERO}

"Se la vita fosse semplice, se le cose fossero tanto poco complicate... Non lo è, però, e le cose sono infinitamente più complesse, mentre il bene e il male non esistono separati, proprio come in natura non esiste ne' il bianco ne' il nero"

Vincent Van Gogh
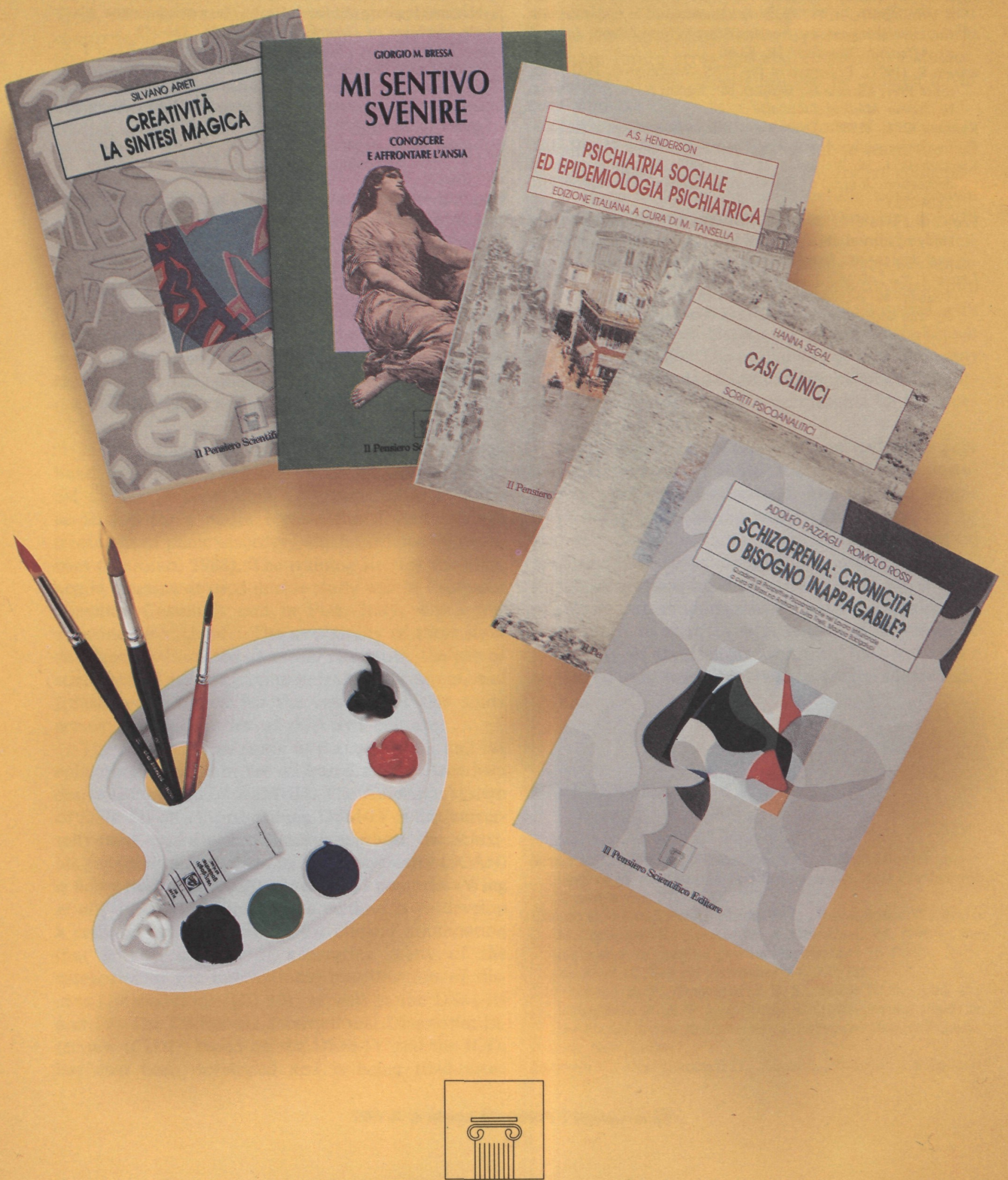